\title{
High-Pitch Computed Tomography of the Lung in Pediatric Patients: An Intraindividual Comparison of Image Quality and Radiation Dose to Conventional 64-MDCT
}

\section{High-pitch Computertomografie der Lunge bei Kindern: Ein intraindividueller Vergleich der Bildqualität und Strahlendosis zur konventionellen 64-MDCT}

Authors

Affiliations
I. Tsiflikas ${ }^{1}$, C. Thomas ${ }^{1}$, D. Ketelsen ${ }^{1}$, G. Seitz² , S. Warmann², C. D. Claussen¹, J. F. Schäfer ${ }^{1}$

Diagnostic and Interventional Radiology, University Hospital of Tuebingen

Pediatric Surgery, University Hospital of Tuebingen
Key words

(-) thorax

- CT

- artifacts

received 20.12.2013

accepted 31.3.2014

Bibliography

Dol http://dx.doi.org/

10.1055/s-0034-1366426

Published online: 22.4 .2014

Fortschr Röntgenstr 2014; 186:

585-590 @ Georg Thieme

Verlag KG Stuttgart · New York . ISSN 1438-9029

\section{Correspondence \\ Dr. Ilias Tsiflikas}

Diagnostic and Interventional Radiology, University Hospital of Tuebingen Hoppe-Seyler-Str. 3

72076 Tübingen

Germany

Tel.: ++ 49/70 71/2986677

Fax: ++49/70 71/2958 45

ilias.tsiflikas@med.uni-

tuebingen.de

License terms

\section{Zusammenfassung \\ $\nabla$}

Ziel: Ziel der Studie war die Häufigkeit von typischen Artefakten der high-pitch Computertomografie (HPCT) bei low-dose Untersuchungen von Kindern im Vergleich zur MDCT zu evaluieren und die effektive Dosis $\left(D_{\text {eff }}\right)$ zu berechnen.

Material und Methoden: 35 Patienten (17 Jungen, 18 Mädchen; Durchschnittsalter $112 \pm 69$ Monate) wurden in diese retrospektive Studie eingeschlossen. Bei allen Patienten wurden zwei CT-Untersuchungen mit jeweils gleicher Röhrenspannung und -strom im mittleren Zeitabstand von 87 Tagen durchgeführt: entweder zuerst die MDCT gefolgt von der HPCT oder in umgekehrter Reihenfolge. Die Bildqualität wurde durch 2 Radiologen im Konsensus intraindividuell verglichen. Der Gesamtartefaktscore $(0-8)$ wurde definiert als Summe der Artefakte durch Bewegung, Atmung sowie Pulsation am Herzen bzw. den pulmonalen Gefäßen (0 - keine; 1 - geringe; 2 - deutliche Artefakte). Die $\mathrm{D}_{\text {eff }}$ wurde entsprechend den Europäischen Leitlinien zur Qualitätssicherung in der MDCT berechnet. Zur Auswertung der Unterschiede zwischen den Gruppen wurde die Mann-Whitney U Teststatistik angewandt. Die Korrelation von ordinalen Variabeln wurde mittels der Spearmans Rangkorrelation getestet.

Ergebnisse: Die Scanzeit war für die HPCT im Vergleich zur MDCT signifikant niedriger $(0,72 \pm$ $0,13 \mathrm{~s}$ vs. $3,65 \pm 0,81 \mathrm{~s} ; \mathrm{p}<0,0001)$. In 28 von 35 (80\%) HPCT Untersuchungen traten keine Artefakte auf, wohingegen bei der MDCT bei allen Untersuchungen Artefakte erkennbar waren. Die Häufigkeit von Pulsations- und Atmungsartefakten war in der MDCT höher im Vergleich zur HPCT ( $100 \%$ vs. $17 \%$ und $31 \%$ vs. $6 \%$ ). Der Gesamtartefaktscore korreliert signifikant mit dem Patientenalter für die MDCT $(r=-0,42 ; p=0,01)$ aber nicht für die HPCT $(r=-0,32 ; p=0,07)$. Die berechnete $D_{\text {eff }}$ war signifikant niedriger für

\section{Abstract \\ $\nabla$}

Purpose: The aim of this study was to investigate frequencies of typical artifacts in low-dose pediatric lung examinations using high-pitch computed tomography (HPCT) compared to MDCT, and to estimate the effective radiation dose $\left(\mathrm{E}_{\mathrm{eff}}\right)$.

Materials and Methods: Institutional review board approval for this retrospective study was obtained. 35 patients (17 boys, 18 girls; mean age $112 \pm 69$ months) were included and underwent MDCT and follow-up scan by HPCT or vice versa (mean follow-up time 87 days), using the same tube voltage and current. The total artifact score $(0-8)$ was defined as the sum of artifacts arising from movement, breathing or pulsation of the heart or pulmonary vessels ( 0 - no; 1 moderate; 2 - severe artifacts). $\mathrm{E}_{\text {eff }}$ was estimated according to the European Guidelines on Quality Criteria for Multislice Computed Tomography. The Mann-Whitney U test was used to analyze differences between the patient groups. The Spearman's rank correlation coefficient was used for correlation of ordinal variables.

Results: The scan time was significantly lower for HPCT compared to MDCT $(0.72 \pm 0.13$ s vs. $3.65 \pm$ $0.81 \mathrm{~s} ; \mathrm{p}<0.0001)$. In 28 of $35(80 \%)$ HPCT examinations no artifacts were visible, whereas in MDCT artifacts occurred in all examinations. The frequency of pulsation artifacts and breathing artifacts was higher in MDCT compared to HPCT (100\% vs. $17 \%$ and $31 \%$ vs. $6 \%$ ). The total artifact score significantly correlated with the patient's age in MDCT $(r=-0.42 ; p=0.01)$, but not in HPCT $(r=-0.32 ; p=0.07)$. The estimated $E_{\text {eff }}$ was significantly lower in HPCT than in MDCT $(1.29 \pm 0.31$ vs. $1.47 \pm 0.37 \mathrm{mSv} ; \mathrm{p}<0.0001$ ).

Conclusion: Our study indicates that the use of HPCT has advantages for pediatric lung imaging with a reduction of breathing and pulsation artifacts. Moreover, the estimated $\mathrm{E}_{\text {eff }}$ was lower. In 
die $\mathrm{HPCT}(1,29 \pm 0,31 \mathrm{mSv}$ vs. $1,47 \pm 0,37 \mathrm{mS}$ für die MDCT; $\mathrm{p}<0,0001)$.

Schlussfolgerung: Die HPCT führt zu einer relevanten Reduktion der typischen Bildartefakte in der Lungenbildgebung bei Kindern. Hierbei ist die berechnete effektive Dosis geringer. Darüber hinaus können die Untersuchungen ohne Sedierung und unter freier Atmung ohne Verlust an Bildqualität durchgeführt werden. Kernaussagen:

- HPCT führt zu einer Reduzierung von Artefakten in der Lungenbildgebung bei Kindern

- Reduzierte $\mathrm{D}_{\text {eff }}$ für die HPCT

- HPCT unter freier Atmung und ohne Sedierung ohne Verlust an Bildqualität addition, examinations can be performed without sedation or breath-hold without losing image quality.

Key points:

- Fewer artifacts in pediatric lung imaging with HPCT

- Reduced $\mathrm{E}_{\text {eff }}$ in HPCT

- HPCT without sedation or breath-hold without loss of image quality

Citation Format:

- Tsiflikas I, Thomas C, Ketelsen D et al. High-Pitch Computed Tomography of the Lung in Pediatric Patients: An Intraindividual Comparison of Image Quality and Radiation Dose to Conventional 64-MDCT. Fortschr Röntgenstr 2014; 186: 585-590

\section{Introduction}

$\nabla$

Multidetector computed tomography (MDCT) has been established as a standard method for evaluating pathological changes of lung parenchyma in children. The most common indications for chest scanning are tumor staging, detection of bronchial anomalies, recurrent infections, diffuse lung diseases and chest trauma [1]. However, strict guidelines for the application of radiation are indispensable and the optimization of examination requirements is essential for radiation protection. Low-dose protocols have been implemented in pediatric CT of the lung since the late $1990 \mathrm{~s}[2,3]$. Additionally, achieving sufficient image quality also in non-compliant patients is imperative. Insufficient results because of motion or repeating scans should clearly be avoided. Hence, there is a need for sedation or controlled ventilation in infants and younger children. The risks and costs of these procedures are definitely not negligible [4].

One approach to eliminate motion and breathing artifacts is accelerating image acquisition by increasing detector width or increasing the pitch. However, using single-source CT, the pitch value is limited to 1.5 for the prevention of sampling gaps.

A second-generation dual-source scanner (SOMATOM Definition Flash, Siemens Healthcare, Forchheim, Germany) allows fast volume scanning with pitch values up to 3.2 [5]. In this high-pitch scanning mode on dual-source CT (DSCT), sampling gaps of the first tube can be filled with data from the second tube.

Previous studies have reported clinical benefits of high-pitch DSCT (HPCT) in cardiac [6-8] and thoracic imaging $[9,10]$. In pe- diatric $\mathrm{CT}$, the high-pitch technique might obviate sedation due to the short acquisition time.

The aim of this study was to evaluate the image quality of HPCT in low-dose pediatric lung examinations in an intraindividual approach compared to standard single-source MDCT.

\section{Materials and methods}

$\nabla$

35 patients ( 17 boys, 18 girls; mean age $112 \pm 69$ months) were included in the analysis. All patients underwent MDCT and a followup scan by HPCT or vice versa in the period from November 2009 to April 2012. Institutional review board approval for this retrospective study was obtained. All CT studies were clinically indicated and written informed consent was obtained from the parents. The underlying diseases and indications for performing CT are listed in $\bullet$ Table 1. The mean interval between HPCT and MDCT was $87 \pm 77$ days. In 28 patients, MDCT was performed as the initial scan and HPCT as the follow-up scan, in 7 patients vice versa. None of the children received sedation. Children below the age of 6 years were examined breathing freely, whereas children older than 6 years received a breathing command. Infants were secured in a commercially available support cushion ( $\bullet$ Fig. 1 ).

The settings for tube current and voltage were identical for MDCT and HPCT according to our standard operating procedure (weight-adapted low-dose protocol, 100 - $120 \mathrm{kVp}, 30$ - $40 \mathrm{mAs}$ ). The following specific scanning parameters were used on 64-slice MDCT (Somatom Sensation 64, Siemens Healthcare, Forchheim,

\begin{tabular}{|lll|}
$\begin{array}{l}\text { number of } \\
\text { patients }\end{array}$ & underlying disease & indication \\
\hline 17 & $\begin{array}{l}\text { malignant hematological malignancies in aplasia } \\
\text { (under HSCT) }\end{array}$ & exclusion/follow-up of pneumonia \\
\hline 7 & $\begin{array}{l}\text { malignant neoplasm } \\
\text { (6 sarcomas, 1HCC) }\end{array}$ & exclusion/follow-up of pulmonary metastases \\
\hline 4 & $\begin{array}{l}\text { blood disorder affecting red blood cells } \\
\text { (2 sickle cell anemia, } 2 \text { thalassemia) }\end{array}$ & exclusion/follow-up of pneumonia \\
\hline 2 & connective tissue disease & follow-up of pulmonary involvement \\
\hline 1 & complex tracheobronchial malformation & initial imaging of anatomy and follow-up in \\
\hline 1 & vACTERL association & search for foreign bodies \\
\hline 1 & tetralogy of Fallot, ARDS & exclusion/follow-up of pneumonia \\
\hline 1 & non-specific hepatopathy, recurrent pneumonia & initial imaging and follow-up of ARDS \\
\hline 1 & nephrotic syndrome, recurrent bronchitis & exclusion/follow-up of pneumonia \\
\hline
\end{tabular}

Table 1 Underlying diseases and indications for scan.

Tab. 1 Zugrunde liegende Erkrankungen und Untersuchungsindikationen.

HSCT: Hematopoietic stem cell transplantation; HCC: Hepatocellular carcinoma; ARDS: Acute Respiratory Distress Syndrome. HSCT: Hämatopoetische Stammzelltransplantation; HCC: Hepatozelluläres Karzinom; ARDS: Acute Respiratory Distress Syndrome. 


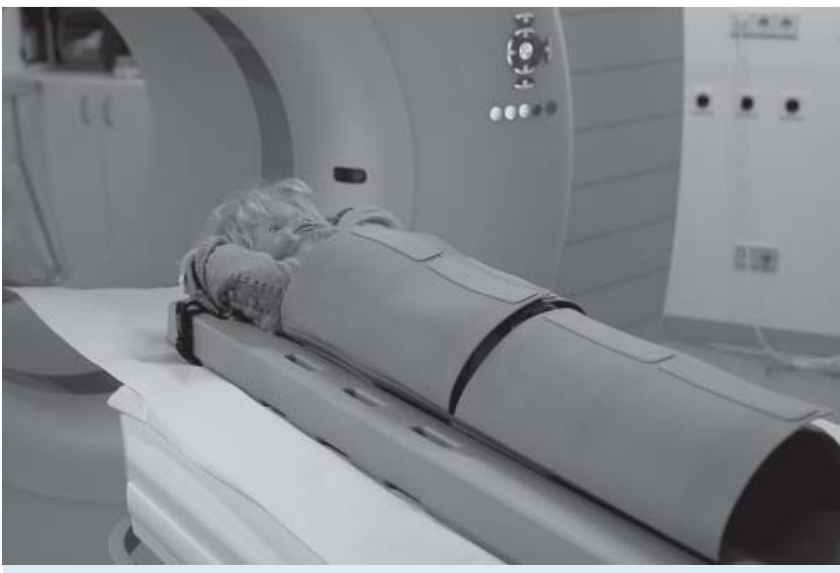

Fig. 1 Support cushion to minimize motion artifacts in infants.

Abb. 1 Lagerungshilfe zur Minimierung der Bewegungsartefakte bei Säuglingen.

Germany): 0.33 seconds gantry rotation time, $64 \times 0.6 \mathrm{~mm}$ slice acquisition using a z-flying focal spot, pitch 1.2. Patients were examined on HPCT using 0.28 seconds gantry rotation time, $128 \times 0.6 \mathrm{~mm}$ slice acquisition using a $z$-flying focal spot, pitch 3.0.

\section{Image reconstruction}

Axial images were reconstructed from the raw dataset using a standard kernel (B31f) with a slice thickness of $3 \mathrm{~mm}$ and an increment of $3 \mathrm{~mm}$ as well as in a high-resolution kernel (B60f) with a slice thickness of $1 \mathrm{~mm}$ and an increment of $5 \mathrm{~mm}$. Further coronal and sagittal reformations were performed in a standard kernel (B 31f) with a slice thickness of $3 \mathrm{~mm}$ and an increment of $2.5 \mathrm{~mm}$ and also a sliding thin-slab MIP (maximum intensity projection) (B50f; slice thickness $6 \mathrm{~mm}$, increment $3 \mathrm{~mm}$ ).

\section{Artifact and image quality evaluation}

All images were evaluated in consensus by two senior radiologists on a standard PACS workstation (Centricity RA 1000, GE Healthcare, Waukesha, Wisconsin, USA). Images of both examinations of each patient were evaluated simultaneously with both observers being blinded for all identifying data and technical details. In this intraindividual approach artifacts arising from movement, breathing or pulsation of the heart or pulmonary vessels were classified according to the following ordinal scale: 0 no artifacts; 1 - moderate artifacts; 2 - severe artifacts. The artifact values were summed up to a total score for each examination ranging from 0 to 8 points. The impression of small normal findings (e.g. sharp visualization of bronchi or septa) was estimated in an intraindividual comparison ( 0 - equal or 1 - superiority of one CT examination). A third radiologist, who was not blinded for identifying data and technical details, assigned results to the corresponding examination.

\section{Radiation dose}

The effective radiation dose ( $\mathrm{E}_{\text {eff }}$ ) of CT examinations was estimated according to the European Guidelines on Quality Criteria for Multislice Computed Tomography proposed by the European Study Group of radiologists and physicists [11]. The effective radiation dose was calculated by multiplying the dose-length product (DLP) with a conversion coefficient $k$ that is specific for different body regions and patient ages $\left(\mathrm{E}_{\text {eff }}=\mathrm{DLP} \times k\right)$. $k$ values for examinations of the thorax are as follows: newborns $k=0.039,1$ year
Table 2 Conversion factors from DLP $(\varnothing 32 \mathrm{~cm})$ to DLP $(\varnothing 16 \mathrm{~cm})$.

Tab. 2 Konversionsfaktoren von DLP $(\varnothing 32 \mathrm{~cm})$ auf DLP $(\varnothing 16 \mathrm{~cm})$.

\begin{tabular}{|c|c|c|}
\hline pediatric body & $\begin{array}{l}\text { Siemens Somatom } \\
\text { Definition Flash }\end{array}$ & $\begin{array}{l}\text { Siemens Somatom } \\
\text { Sensation } 64\end{array}$ \\
\hline $70 \mathrm{kV}$ & 2.4 & n. a. \\
\hline $80 \mathrm{kV}$ & 2.3 & 2.2 \\
\hline $100 \mathrm{kV}$ & 2.2 & 2.1 \\
\hline $120 \mathrm{kV}$ & 2.2 & 2.0 \\
\hline $140 \mathrm{kV}$ & 2.2 & 2.0 \\
\hline
\end{tabular}

$\mathrm{k}=0.026,5$ years $\mathrm{k}=0.018,10$ years $\mathrm{k}=0.013$ and for adults $\mathrm{k}=0.014$ [11]. Both DLP and CTDI $\mathrm{vol}_{\mathrm{l}}$ were recorded from electronic patient protocols that summarized the individual radiation exposure parameters of each CT acquisition. Both CT scanners used in this study supply a $\mathrm{CTDI}_{\mathrm{vol}}$ referring to a $32-\mathrm{cm}$ body phantom. However, for pediatric patients $k$ refers to a $16-\mathrm{cm}$ body phantom so that the volume CT dose index $\left(\mathrm{CTDI}_{\mathrm{vol}}\right)$ as well as the DLP had to be converted to a $16-\mathrm{cm}$ phantom using a scanner-specific additional converting factor provided by the manufacturer ( $\bullet$ Table 2 ).

\section{Statistical analysis}

Statistical analysis was performed using commercially available software (SAS jmp, release 11.0 for Windows, SAS Institute Inc., Cary, NC, USA). Continuous variables were expressed as mean \pm standard deviations, and categorical variables were expressed as frequencies. Additionally, median values were provided where appropriate. The Mann-Whitney $U$ test was used to analyze differences between the study groups. The Spearman's rank correlation coefficient was used for correlation of ordinal variables. P values below 0.05 were considered statistically significant.

\section{Results}

All examinations were performed successfully in both HPCT and MDCT, and no scan had to be repeated. As expected from our experience with conventional X-ray examinations, all children tolerated fixation in the support cushion without significant resistance. In HPCT the mean scanning time was $0.72 \pm 0.13 \mathrm{~s}$ compared to $3.65 \pm 0.81 \mathrm{~s}$ in MDCT $(\mathrm{p}<0.0001)$. Thus, the mean time saving in HPCT was $2.93 \pm 0.68 \mathrm{~s}$.

The mean scanning range was $29.4 \pm 5.5 \mathrm{~cm}$ in HPCT and 25.5 $\pm 5.7 \mathrm{~cm}$ in $\operatorname{MDCT}(\mathrm{p}=0.0035)$. In all patients except one, the scanning range was larger in HPCT, even in those patients, in whom HPCT was performed as the initial scan. The mean difference between both scanning methods was $3.9 \pm 1.9 \mathrm{~cm}$ resulting in a relative difference of $17 \%$. The highest relative difference of $23 \%$ was found in the first third of HPCT examinations.

The overall image quality was excellent for HPCT with no artifacts in 28 examinations ( $80 \%$ ) whereas in MDCT artifacts occurred in all examinations. There was a higher frequency of breathing artifacts in MDCT (11 examinations, 31\%) compared to HPCT (2 examinations, $6 \%$ ). Pulsation artifacts next to the heart were found in all MDCT examinations, and in 6 HPCT examinations (17\%). All patients were examined without moving artifacts irrespective of the scan mode. Details are given in $\bullet$ Table 3. The total artifact score was significantly lower for HPCT $0.26 \pm 0.56$ (median 0 ; range $0-2$ ) than for MDCT $2.46 \pm 1.31$ (median 2; range 1-6) $(\mathrm{p}<0.0001)$. The patient's age significantly correlated with the 
total artifact score in MDCT $(r=-0.42 ; p=0.01)$, but not in HPCT $(\mathrm{r}=-0.32 ; \mathrm{p}=0.07)$

The depiction of small objects was rated equal for both scanning modes in 26 examinations (74\%), superior for HPCT in 8 examinations (23\%), and superior for MDCT in 1 examination (3\%).

Examples of differences in image quality are shown in 0 Fig. $2,3$. Mean effective radiation dose $\mathrm{E}_{\text {eff }}$ was significantly lower in HPCT $(1.29 \pm 0.31 \mathrm{mSv})$ compared to MDCT $(1.47 \pm 0.37 \mathrm{mSv}, \mathrm{p}<0.0001)$ (0 Fig.4).

\section{Discussion}

$\nabla$

Pediatric patients, especially young children and infants, benefit from lower radiation doses, and investigators benefit from better image quality (because of fewer artifacts) in HPCT compared to MDCT.

Our study supports the interindividual comparison of Lell et al. [10] who have shown a lower rate of image artifacts in pediatric chest HPCT compared to 10 or 64-row MDCT. We compared both scanning modes using an intraindividual study design with a

Table 3 Rating of artifacts in MDCT and DSCT.

Tab. 3 Bewertung der Artefakte für MDCT und DSCT.

\begin{tabular}{|lcccccc|}
\hline & MDCT & \multicolumn{5}{c|}{ DSCT } \\
\hline artifacts & $\mathbf{0}$ & $\mathbf{1}$ & $\mathbf{2}$ & $\mathbf{0}$ & $\mathbf{1}$ & $\mathbf{2}$ \\
\hline movement & 35 & 0 & 0 & 35 & 0 & 0 \\
\hline breathing & 24 & 5 & 6 & 33 & 2 & 0 \\
\hline pulsation heart & 0 & 23 & 12 & 29 & 6 & 0 \\
\hline pulsation vessels & 15 & 18 & 2 & 34 & 1 & 0 \\
\hline
\end{tabular}

Bold numbers indicate the severity of artifacts: 0 - no artifacts; 1 - moderate artifacts; 2 - severe artifacts. Cursive numbers are frequencies.

Die fett geschriebenen Nummern entsprechen dem Schweregrad der Artefakte: 0 - keine Artefakte; 1 - geringe Artefakte; 2 - deutliche Artefakte. Die kursiv geschriebenen Nummern entsprechen den Häufigkeiten. mean time interval of 87 days. As shown in the present study, breathing artifacts occurred in only two HPCT examinations, but in 11 children examined with MDCT. The benefit of rapid scan was also clearly shown in the considerably lower rate of pulsation artifacts: in HPCT they occurred in 6 patients next to the mediastinum and in only 1 patient next to the pulmonary vessels. In MDCT they occurred in 35 and 20 patients, respectively. There were no moving artifacts observed in either scanning mode, which can be related to the use of a support cushion assuring secure fixation of small children and infants.

The superiority of HPCT image quality, especially the reduction of pulsation artifacts, possibly results in an improved detection rate of pathological pulmonary findings. In the past, several approaches were described to increase detection rates of pulmonary pathologies by reducing pulsation artifacts, for example with ECG-triggering. Pauls et al. showed the superiority of ECG-triggered MDCT in detecting pulmonary nodules [12]. In their study including 50 patients with malignant tumors, ECG-triggered MDCT detected $38 \%$ more pulmonary nodules (64\% more pulmonary nodules $<5 \mathrm{~mm}$ ) than non-triggered MDCT. Nevertheless, ECG-triggered MDCT results in an increased radiation dose. This application in pediatric patients is therefore not suitable, except in specially indicated cases. HPCT clearly delineated small pulmonary nodules next to the mediastinal borders potentially being superimposed by pulsation artifacts in MDCT as shown in - Fig. 3. We believe that the use of HPCT has a relevant clinical impact in patients with pulmonary metastases. Fuchs et al. observed a lower number of pulmonary metastases in preoperative MDCT in 5 of 16 tumor patients compared to intraoperative status [13]. Grundy et al. have shown that Wilms' tumor patients with metastatic lung disease undergoing therapy with 3 instead of 2 drugs have an improved five-year event-free survival compared to patients with metastases detected by chest radiograph ( $80 \%$ vs. $56 \%$ ) [14]. Furthermore Warmann et al. have shown a poorer outcome in Wilms' tumor patients with persistent metastases after local treatment [15].
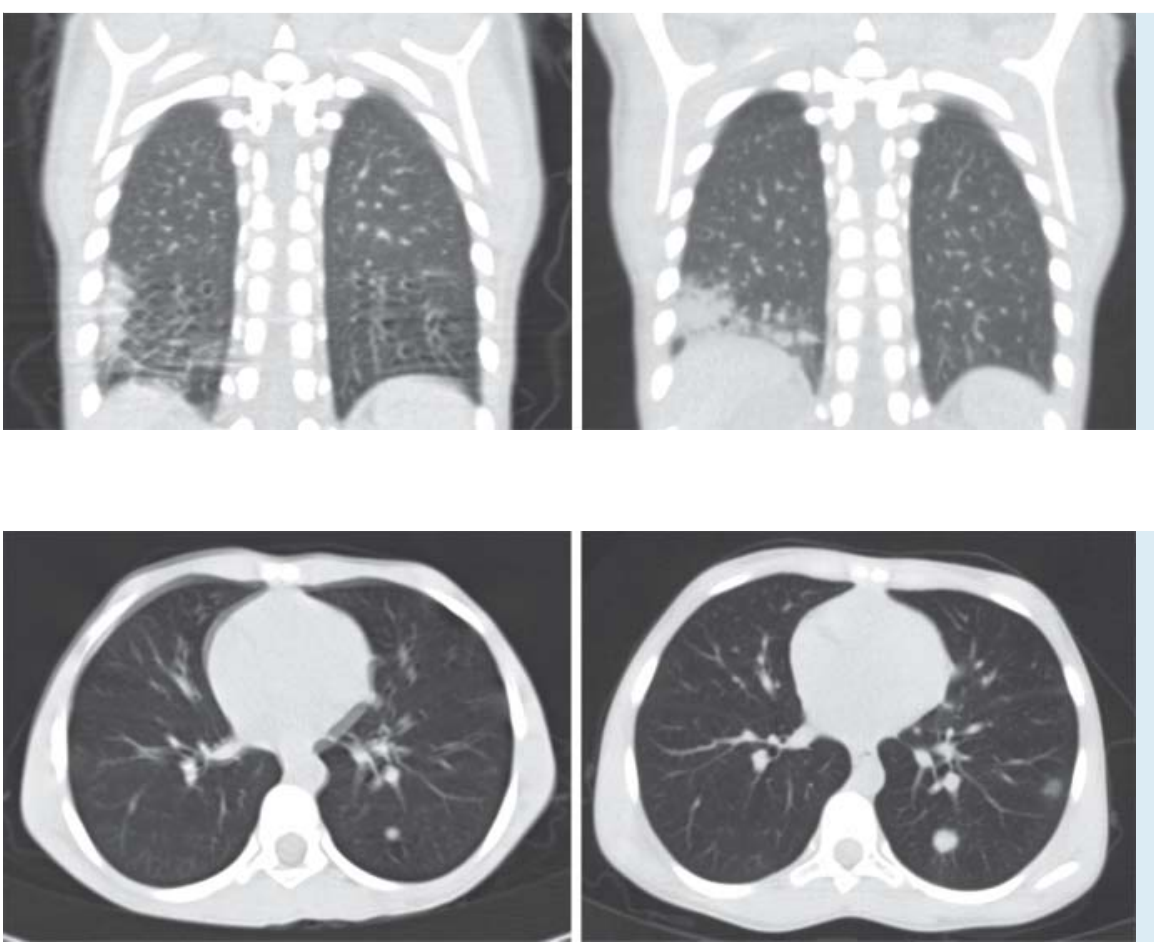

Fig. 3 13-year old boy, osteosarcoma, pulmonary metastasis, follow-up within 79 days, no sedation, breath-hold; left: MDCT, scanning time $4.07 \mathrm{~s}$, severe pulsation artifacts, right: HPCT, scanning time $0.77 \mathrm{~s}$, no artifacts.

Abb. 3 13-jähriger Patient mit Osteosarkom und pulmonalen Metastasen, Verlaufskontrolle nach 79 Tagen, keine Sedierung, Atemkommando; links: MDCT, Scanzeit 4,07 s, deutliche Pulsationsartefakte, rechts: HPCT, Scanzeit $0,77 \mathrm{~s}$, keine Artefakte. 


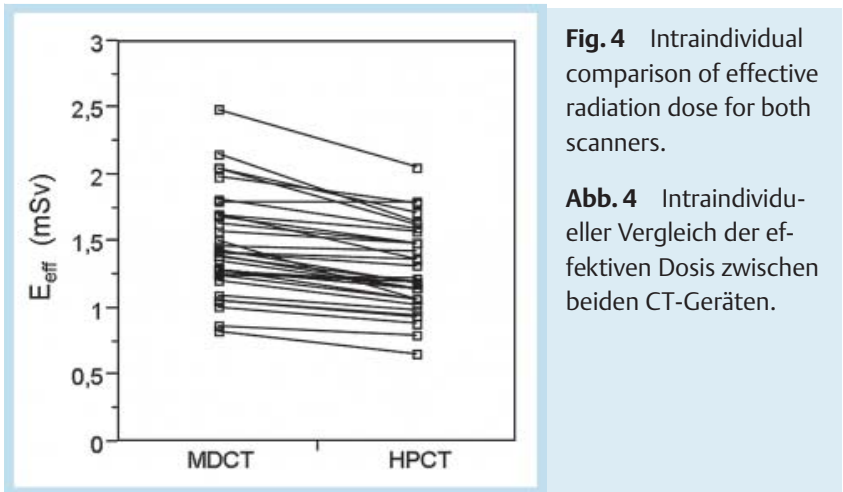

Kroft et al. took a different approach in speeding up imaging acquisition and thereby increasing image quality of thoracic CT in infants [16]. They used a 320-detector-row MDCT that allows axial volumetric scanning of a $16-\mathrm{cm}$-long range. The performed phantom study has shown that in small children the entire scanning range could be acquired in $0.35 \mathrm{~s}$, leading to a significant reduction of acquisition time compared to conventional helical scanning. However, the shortest HPCT scanning time in our study was comparable $(0.47 \mathrm{~s}$, scan range of $19.2 \mathrm{~cm})$. Moreover, HPCT is also a valuable tool for larger scanning ranges in older children with a maximum scanning time of $1 \mathrm{~s}$.

Beyond an increased image quality, HPCT improves the workflow in pediatric CT. Performing all examinations without sedation or even controlled ventilation requires less staff. The presence of an anesthesiologist is unnecessary and there is no need for a rest and surveillance period after examination. Thus, procedural times and costs may be reduced [17]. An even more essential disadvantage of anesthesia is the possible influence on the developing brain. In a recently published study, Ing et al. showed that children below the age of 3 exposed to anesthesia had a higher relative risk of language and abstract reasoning deficits by the age of 10 compared to unexposed children [18]. In a meta-analysis of 12 studies, DiMaggio et al. could also show an association between pediatric anesthetic agents in the setting of surgery and subsequent learning or behavioral problems in children [19]. Anesthesia-related atelectases is another issue, leading to decreased image quality and possibly masking substantial pathological findings. Sargent et al. showed significant atelectases in up to $68 \%$ of children undergoing CT under sedation [20]. Even using optimized ventilation protocols, there still can be atelectases found in up to $29 \%$ of examinations as recently shown by Newmann et al. [21].

Radiation exposure is another important aspect in pediatric CT. Although there was an increase in z-overscanning with higher pitch values, we observed a mean decrease in effective radiation dose of about $12 \%$. This seems to be related to the bowtie-shaped aluminum filter used in the high-pitch mode. Co et al. showed a $48 \%$ dose reduction in their study using an ultra-high-pitch CT pulmonary angiography protocol with cardiac bowtie-shaped filter [22]. Taking into account that scanning range was longer in HPCT in 34 of 35 patients, the potential dose reduction was underestimated. This overranging seems to be a major limitation of HPCT. However, we found a relationship to the learning curve of the technicians with the highest relative difference in the first third of the examinations.

There are some limitations in our study. First, it was a retrospective single center study in a relatively small pediatric population.
Second, the wide age distribution in our study may underestimate the benefits of high-pitch scanning for infants. Third, an inconsistent time interval between the two CT examinations has to be considered that may have hampered the comparability.

In conclusion, our study indicates that the use of high-pitch DSCT has advantages for pediatric lung imaging by reducing breathing and pulsation artifacts. Moreover, the estimated effective radiation dose was reduced. In addition, examinations can be performed without sedation or breath-hold, even in infants and uncooperative children, without a loss of image quality.

\section{References}

1 Nievelstein RA, van Dam IM, van der Molen AJ. Multidetector CT in children: current concepts and dose reduction strategies. Pediatr Radiol 2010; 40: $1324-1344$

2 Rogalla P, Stover B, Scheer I et al. Low-dose spiral CT: applicability to paediatric chest imaging. Pediatr Radiol 1999; 29: 565-569

3 Singh S, Kalra MK, Moore MA et al. Dose reduction and compliance with pediatric CT protocols adapted to patient size, clinical indication, and number of prior studies. Radiology 2009; 252: 200-208

4 Sury M, Bullock I, Rabar S et al. Sedation for diagnostic and therapeutic procedures in children and young people: summary of NICE guidance. BMJ 2010; 341: c6819

5 Flohr TG, Leng S, Yu L et al. Dual-source spiral CT with pitch up to 3.2 and $75 \mathrm{~ms}$ temporal resolution: image reconstruction and assessment of image quality. Med Phys 2009; 36: 5641 -5653

6 Hausleiter J, Bischoff B, Hein F et al. Feasibility of dual-source cardiac CT angiography with high-pitch scan protocols. J Cardiovasc Comput Tomogr 2009; 3: 236-242

7 Leschka S, Stolzmann P, Desbiolles L et al. Diagnostic accuracy of highpitch dual-source $\mathrm{CT}$ for the assessment of coronary stenoses: first experience. Eur Radiol 2009; 19 (12): 2896-2903

8 Alkadhi H, Stolzmann P, Desbiolles L et al. Low-dose, 128-slice, dualsource CT coronary angiography: accuracy and radiation dose of the high-pitch and the step-and-shoot mode. Heart 2010; 96: 933-938

9 Lell M, Hinkmann F, Anders K et al. High-pitch electrocardiogram-triggered computed tomography of the chest: initial results. Invest Radiol 2009; 44: $728-733$

10 Lell MM, May M, Deak P et al. High-Pitch Spiral Computed Tomography: Effect on Image Quality and Radiation Dose in Pediatric Chest Computed Tomography. Invest Radiol 2010

11 Bongartz GSJG, Jurik AG, Leonardi M et al. European Guidelines on Quality Criteria for Multislice Computed Tomography. In: Commission E. ed. FIGM-CT2000-20078-CT-TIP Luxembourg: 2004

12 Pauls S, Aschoff AJ, Wahl J et al. Multi-detector row CT: is prospective electrocardiographic triggering improving the detection of small pulmonary tumors? Acad Radiol 2005; 12: 614-619

13 Fuchs J, Seitz G, Ellerkamp V et al. Analysis of sternotomy as treatment option for the resection of bilateral pulmonary metastases in pediatric solid tumors. Surg Oncol 2008; 17: 323-330

14 Grundy PE, Green DM, Dirks AC et al. Clinical significance of pulmonary nodules detected by CT and Not CXR in patients treated for favorable histology Wilms tumor on national Wilms tumor studies-4 and -5: A report from the Children's Oncology Group. Pediatr Blood Cancer 2012

15 Warmann SW, Furtwangler R, Blumenstock $G$ et al. Tumor biology influences the prognosis of nephroblastoma patients with primary pulmonary metastases: results from SIOP 93-01/GPOH and SIOP 2001/GPOH. Annals of surgery 2011; 254: 155-162

16 Kroft LJ, Roelofs JJ, Geleijns J. Scan time and patient dose for thoracic imaging in neonates and small children using axial volumetric 320-detector row CT compared to helical 64-, 32-, and 16- detector row CT acquisitions. Pediatr Radiol 2010; 40: 294-300

17 Vanderby SA, Babyn PS, Carter MW et al. Effect of anesthesia and sedation on pediatric MR imaging patient flow. Radiology 2010; 256: 229-237

18 Ing C, DiMaggio C, Whitehouse A et al. Long-term differences in language and cognitive function after childhood exposure to anesthesia. Pediatrics 2012; 130: e476-e485

19 DiMaggio C, Sun LS, Ing C et al. Pediatric anesthesia and neurodevelopmental impairments: a Bayesian meta-analysis. Journal of neurosurgical anesthesiology 2012; 24: 376 -381 
20 Sargent MA, McEachern AM, Jamieson DH et al. Atelectasis on pediatric chest CT: comparison of sedation techniques. Pediatr Radiol 1999; 29: 509-513

21 Newman B, Krane EJ, Gawande R et al. Chest CT in children: anesthesia and atelectasis. Pediatr Radiol 2013

22 Co SJ, Mayo J, Liang T et al. Iterative reconstructed ultra high pitch CT pulmonary angiography with cardiac bowtie-shaped filter in the acute setting: effect on dose and image quality. Eur J Radiol 2013; 82: 1571 1576 